\title{
Morphology and Histology of the Digestive System of the Red Palm Weevil Larva, Rhynchophorus ferrugineus, Olivier (Coleoptera: Dryophthoridae)
}

\author{
M. N. Harris ${ }^{1}$, J. J. Norzainih ${ }^{1} \&$ O. Nurul Wahida ${ }^{1}$
}

\begin{abstract}
The red palm weevil (RPW), Rhynchophorus ferrugineus is the major pest of the palms that originate from Southeast Asia and Melanesia. Although RPW is an economic important pest there is still no study conducted on its digestive morphology and mechanisms that relates majorly for the destruction of the palm trees. This study has been conducted to understand the alimentary system of the red palm weevil larvae. RPW larvae is known to be the most vicious as it is active at this developmental stage as its feeding activity on the stem contributes to the destruction of the palm tree. Samples were taken from Terengganu, Malaysia and reared in the laboratory. The result revealed that the alimentary tract is consists of three part; foregut, midgut and hindgut with foregut, consist of an oesophagus, crop and proventriculus. The crop is having the largest portion in the foregut, supporting its role in storing the solid food of active feeding larvae. The proventriculus lies at the posterior of foregut the site where the solid food will grinded into small pieces. The midgut is the longest part of the alimentary tract, coiled inside the abdominal segments. The ventriculus of the midgut is covered with the projection of criptae papillae on the surface. The midgut epithelium can be characterized by the present of the columnar cell, goblets cell, villi and peritrophic membrane. The hindgut is located at the most posterior part of the alimentary tract that consist of the ileum, Malpighian tubule, colon and rectum. Another significant finding is the arrangement of the Malpighian tubule for RPW are classified as cryptonephridial type of arrangement based on the histology result, it is fused into the ileum and the colon, located between the ileum and the rectum of the larvae. There might be a potential solution for RPW infestation through the understanding if their digestive system.
\end{abstract}

Key words: RPW, Rhynchophorus ferrugineus digestive system, larvae

\section{INTRODUCTION}

$\mathrm{T}$ THE red palm weevil (RPW) larvae undergo seven to eight larva instar stages based on observation that have been carried out in our laboratory. Most of the larvae undergo up to seventh instar stage throughout the observation process. However some of the larvae were manage to develop until eight instar stage after eight day but more than half of the larvae have turned into cocoon inside

\footnotetext{
${ }^{1}$ Centre of Insect Systematic, School of Environmental Science and Natural Resources Sciences, Faculty of Science and Technology, Universiti Kebangsaan Malaysia, 43600 UKM Bangi, Selangor, Malaysia.
}

the sugar cane blocks. The previous study of larva stage development mostly show below than seven larva instar except for Jaya et al. (2000) that recorded the same larva stage as we are, while others recorded more than seven that up to 17 larva instar [17;21]. The result were also supported by Dyar's rule [9], which hypothesizes a geometric head capsule growth that considered satisfactorily be used to determine the larva instar stages. Red palm weevil completed its larva period in 70 days in this observation. The result were consistent with the data written by other authors for $R$. ferrugineus which is the development for the larva stage range from 24 days to 128 days [7]. The data may differ based on the different diets used for the larva development. The number for development of larva can also been altered by other external factors, temperature and their interaction [22;24].

The digestive tract are the most important organs for insect for supplying the nutrient needed for the growth and to carry out daily activities. The alimentary system of insect can be divided into three part: the foregut, midgut and hindgut $[1 ; 6]$, however, different structure can be observed among species due to the differences in dietary habits. Red palm weevil, Rynchophorus ferrugineus is a well-known pest for palm plantation in the trophic and subtropical region of the world that have been an economic important pest.

The larvae feed on the trunk of the palm tree thus creating empty cavities inside the tree that lead to the dead of the tree without any physical symptom appeared on the infested tree. The most destructive stage of this insect toward the palm tree is the larval stage. Although RPW is an economic important pest there still no study conducted to study the digestion system of this insect and the mechanism in supplying nutrition for their survival. The purpose of this study was to provide a fundamental information on the morphology and histology of the alimentary tract or RPW larvae

\section{II.MATERIALS AND METHODS}

\section{A. Samples}

The larvae of RPW used for this study were reared in the laboratory. The rearing room is keep under temperature between $26^{\circ} \mathrm{C}$ to $34^{\circ} \mathrm{C}$ with relative humidity level between $59 \%$ and $80 \%$. The photo period was approximately 12:12 L:D. Larvae from $6^{\text {th }}$ instar were used in this study as it is 
the most active stages of feeding and the structure is easier to be dissected and observed.

\section{B. Morphology Study}

The larvae were immobilized in a freezer at $4^{\circ} \mathrm{C}$ for 30 minutes and their gut were dissected. Phosphate buffer saline (PBS) were used to keep the gut from drying. The gut were then photograph in-situ and ex-situ with Leica EZ4 HD Stereo Microscope with Las EZ software for morphological study. For storage purposes, the digestive tract was placed in $10 \%$ formalin solution.

\section{Histology Study}

For studies with light microscope, the gut were fixed in $10 \%$ formalin buffer solution for 24 hours. They were dehydrated in graded ethanol series; $70 \%, 80 \%, 95 \%$ and $100 \%$. The samples was cleared in xylene for 30 minutes for two times. The sample were then embedded in paraffin wax and allowed to solidify. The paraffin sections (3-4 $\mu \mathrm{m})$ were cut using using a Reichert microtome and tissue section are stained with Pacific Acid Schiff (PAS) and Alcian blue solutions. The glass slide was then mounted with DPX mounting. Images of tissue section were analysed and photographed using Zeiss Axio Scope light microscope with iSolutionLite software.

\section{RESULT AND DisCUSSION}

\section{A. Morphology of the Digestive Tract}

The digestive tract of RPW larvae is slightly different in structure compare to the adult based on their mode of feeding. RPW larvae have mouth of a mandibular type since they are feeding on the fibrous plant. Chapman (1998) has described a mandibular type mouthpart for solid feeding insect. Larvae organ are larger and a bit more longer than the adult. Larger organ is needed since the larvae consume more food because it uses more energy for eclosion and the periodic moulting of its cuticle [3]. The gut can be divided into three part; the foregut, midgut and the hindgut with different structure at different part (Fig 1). The gut shows a resemblance with some of the coleopteran species like Bolitotherus cornutus larvae, Cephalodesmius armiger and platynotus belli $[2 ; 18 ; 20]$.

The foregut is the largest part of alimentary tract of RPW larvae as it covers half of the anterior body cavity and can easily be recognized by the dark appearance once we do the dissection. The foregut is made up of oesophagus, crop and elongated to the proventriculus. The crop is the largest structure of the larva gut as it is for the storage of the food taken by the larvae before moving through the proventriculus. The crop can expend to its maximum size for storage of food. By referring to the size and length of the foregut, the foregut isn't just functioning as the site for food storage and grinding but it may function as well as the site for nutrition absorption and food digestion since the larvae consume fibrous foodlike what have been observe in some of orthopteran species, Abraccris flavolieneata where the absorption of nutrient starts at the crop of the insect [24]. Unlike the adult, the larvae do not possess any scleratize structure inside the proventriculus.

The midgut is the shortest structure of RPW larvae and can be easily recognize as it only consist of ventriculus with criptae papilae. The ventriculus is known as the site where the food digestion and absorption occurs within the insect digestion system. The surface of the ventriculus have a structure emerging from the surface known as criptae papillae that increase the surface area for food absorption since it does not have a gastric caecum on its structure.

Gut structure at the posterior part of the larvae known as the hindgut with the structure of ileum, colon, Malpighian tubule and rectum. The position of the hindgut structure are the same with what have been observe in the adult of RPW but different from other species. Malphigian tubules usually located at the anterior part of the hindgut, acting as the boundaries between midgut and hindgut. However the Malpighian tubules of RPW larvae are located in the middle of the hindgut between colon and the rectum but are more close to the rectum. It enclosed the surface of the rectum covered by a thin layer of colourless membrane. It shared the same structure with its relative larvae species, Rhynchophorus phoenicis Fabricius [19]. The morphology and histology result showed that the Malpighian tubule are a type of cryptonephridial arrangement. The rectum is convoluted a bit at the end of the hindgut. There is no accessory structure that can be observe on the surface of hindgut.

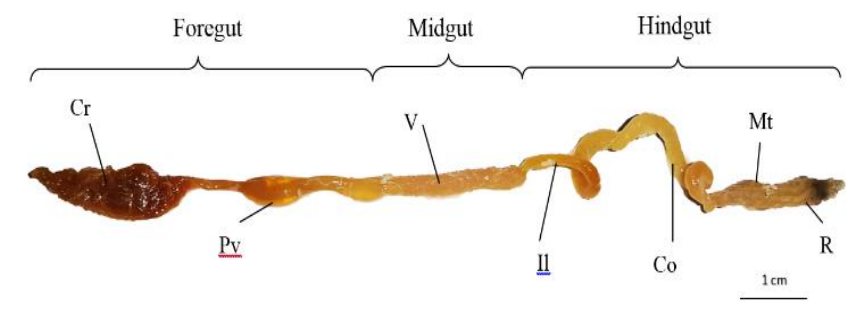

Fig. 4 Ex-situ observation on the internal organ of adult red palm weevil, Rhynchophorus ferrugineus. Crop (Cr); Proventriculus (Pv); Ventriculus (V); Ileum (II); Malpighian tubule (Mt); Rectum (R).

\section{B. Histology of the Digestive Tract}

The crop of RPW larva is made up of single cell layer of non-ciliated pseudostratified columnar epithelium cell. The cell nucleus is big and mostly located near the basement membrane of every cell, stained with dark blue colour shows a high level of acid mucins in this cell (Fig 2A). The cells are tightly packed together that make the cell appears as single cell with two nucleus. The basal membrane of the epithelium cell were stained with bright purple (Fig 2B). This type of cell may function in secretion or absorption. There is a layer covering the apical surface of the epithelium cell that may have been secreted by the cell itself to protect the cell surface from damage due to the friction of food inside the lumen. The absorption of nutrient are possible to be started at the foregut with the presence of this type of cell by surface transport mechanism [4]. The folding structure of the crop allow it to expand further when is needed. No muscle layers appears in this structure. The food were push to the other part of the gut by the continuous feeding habits of the larvae. 

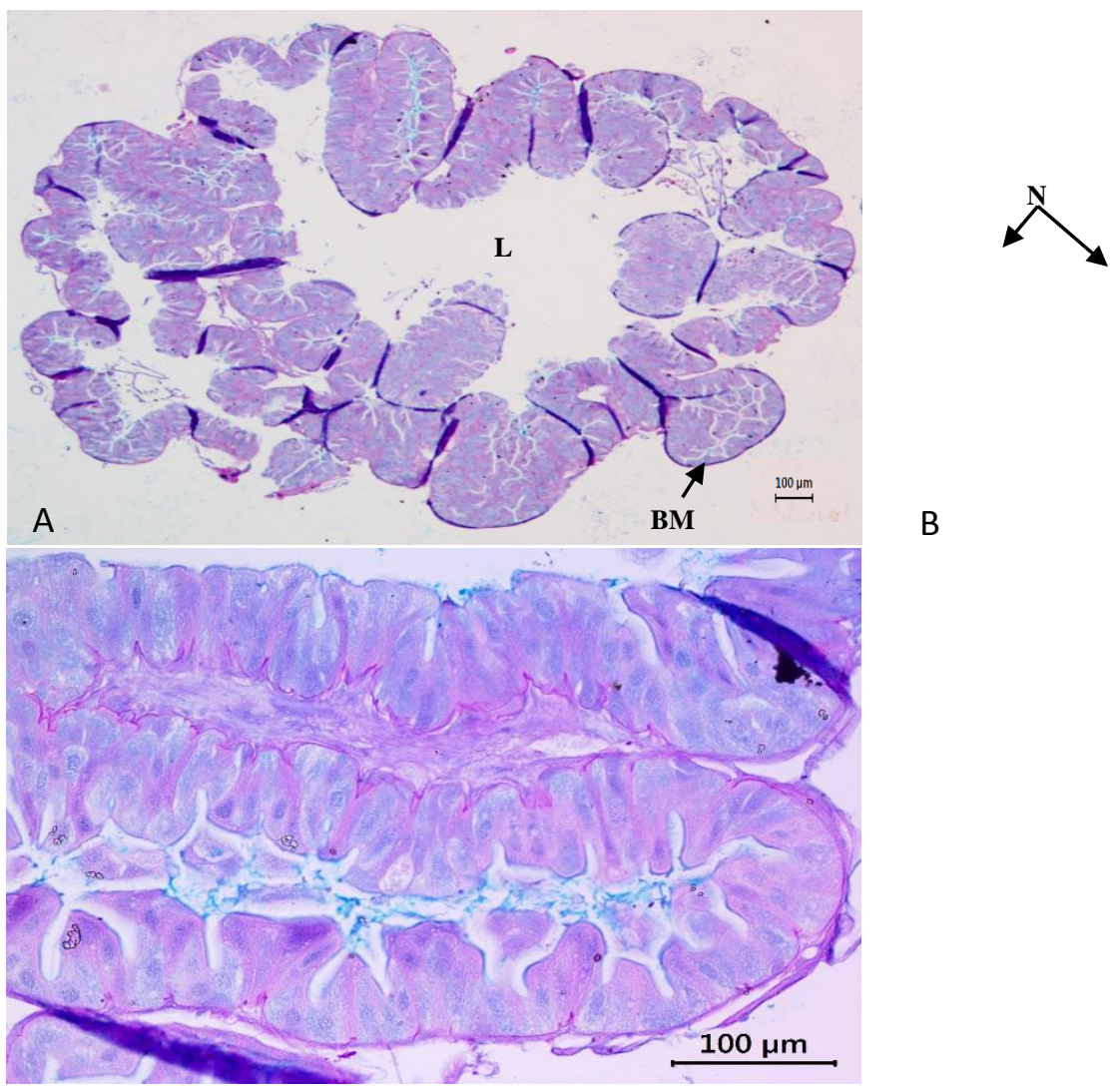

B

BM

PsE

Fig 2 A. Complete histology section of the RPW larva crop. B. Higher magnification of the pseudostratified epithelium cell (PsE) of the crop. Basement membrane (BM); Nucleus (N); Lumen (L)

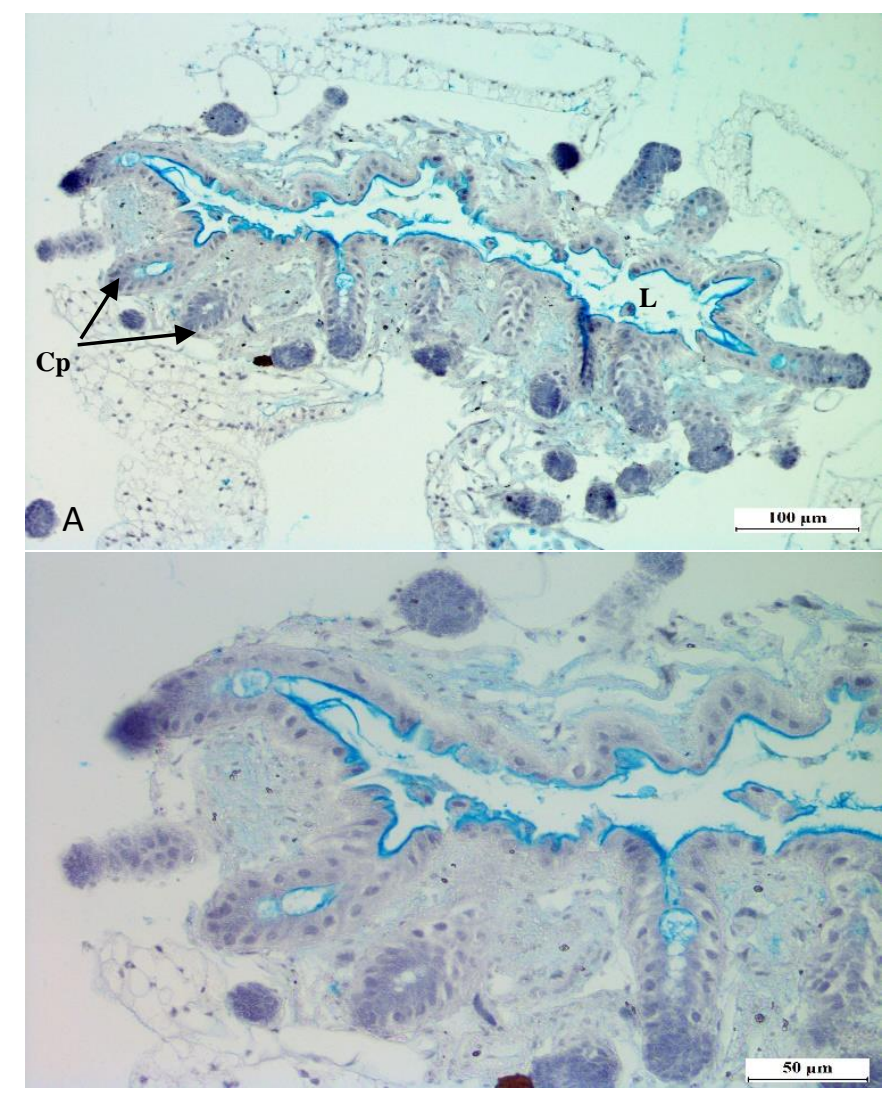

$\downarrow$

$\mathbf{L}$
CoE

L

RC

Fig 3 A. The larvae midgut with criptae papillae (Cp) structure invaginate into the cell. B. Columnar epithelium cell (CoE) layers of the midgut and criptae papillae. Lumen (L); Goblet cell (GC); Regenerative cell (RC). 


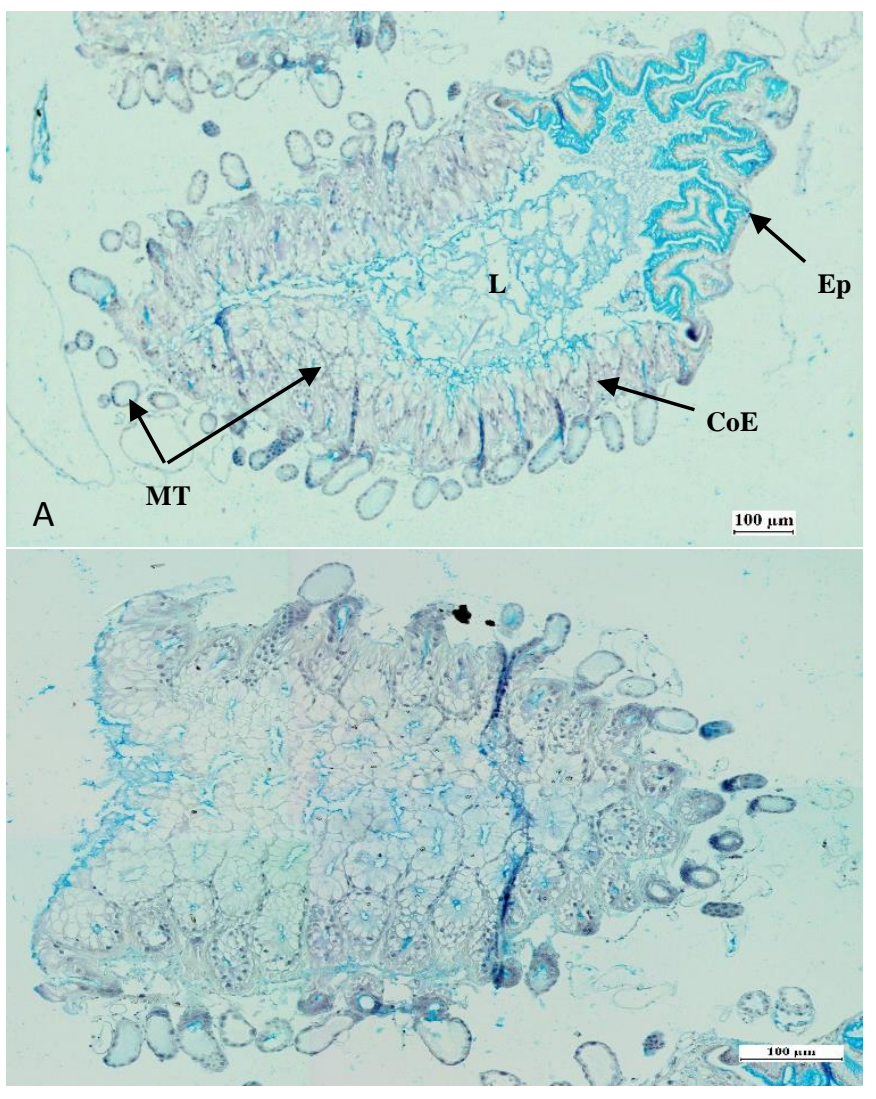

B

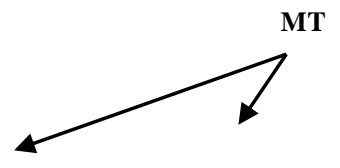

$\mathbf{L}$

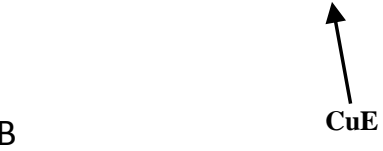

Fig 4 A. Cross section of the illeum with few invagination of Malpighian tubule (MT) within the cell and also at the outside of cell. B. The lumen (L) of colon were closely pack with Malpighian tubule structure leave only a small at the middle. Cuboidal epithelium cell (CuE);

Columnar epithelium cell (CoE); Epithelium cell (Ep) 
Basic cell type of the midgut are present in RPW larva such as goblet cell in between the columnar epithelium cell and degenerative cell at the basal membrane that are important for the digestion and absorption process in the midgut (Fig 3A). Columnar epithelium cell of the midgut are particularly play an important role in secretion of digestion enzyme for food digestion and the absorption of food nutrient into the haemolymph [19]. Peritrophic membrane have not been observe inside the midgut of RPW larvae unlike the one that have been observed in the midgut of it closes family species, the adult of Rhynchophorus phoenicis. But peritrophic membrane are not the only structure that keep the cell from frictional damage from the food molecule. There are another layer protecting the midgut epithelium known as perimicrovillar membrane [23]. The same membrane structure were reported on some hemipteran species, Hemiptera spesies Brontocoris tabidus and Oncopeltus fasciatus $[10 ; 11]$. The structure of criptae papillae have been observe for this species as it invaginates from the outer surface of the midgut towards the lumen (Fig 3B). The criptae papillae are also made up of columnar epithelium cell. It increase the surface area inside the midgut for digestion and secretion process of the food [14]. Layers of longitudinal muscle are surrounding the cell at the outermost layer.

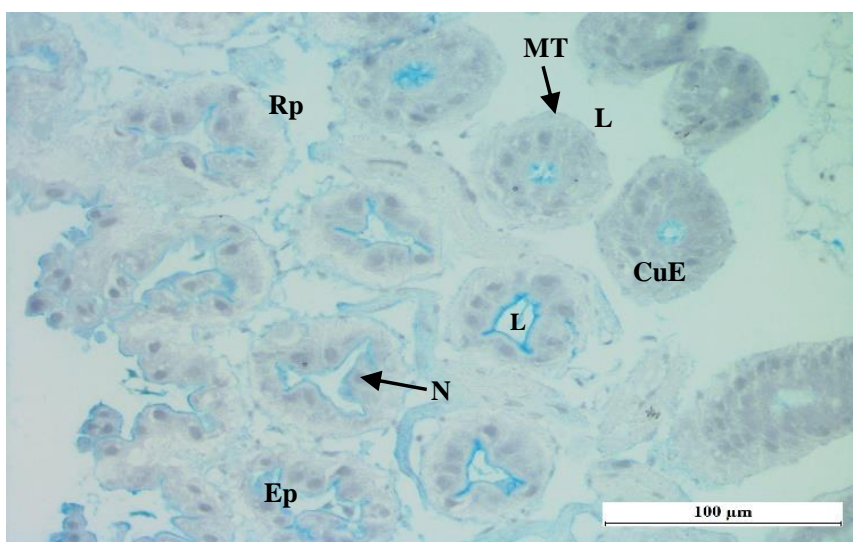

Fig 5 The distal like tubule structure of the Malpighian tubule (MT) with cuboidal epithelium cell (CuE) lining around the lumen (L). Nucleus $(\mathrm{N})$

All part of the hindgut were made up of single layer of cuboidal epithelium cell except for the ileum. For the ileum, single layer of columnar epithelium cell were observed (Fig 4A). The arrangement of the epithelium cell were more closely looked like a transitional epithelium. They were closely packed together with the nucleus located away from the basement membrane at the apical surface. There were folding formation of epithelium cell at the site where the Malpighian tubule were absent. Malpighian tubule cells can be observe within the ileum and at the outside of the ileum but there were differences in their structure. The lumen of the floating Malpighian tubules on the outer surface of the ileum were bigger than the one that invaginate into the lumen of ileum. The lumen of Malpighian tubules inside the lumen of ileum were rather small because of the bigger single cell layer of cuboidal epithelium cell that were surrounding it (Fig 4B). The formation of the Malpighian tubules within the lumen looked alike the collecting tubule cell of human kidney that have the same role as Malpighian tubule for reabsorption of water and useful ion [16]. The epithelium of the outer Malpighian tubules were flat and thin making the lumen bigger. Single cell muscle layer were located at the outermost layer of the ileum surrounding the epithelium structure (Fig 5).

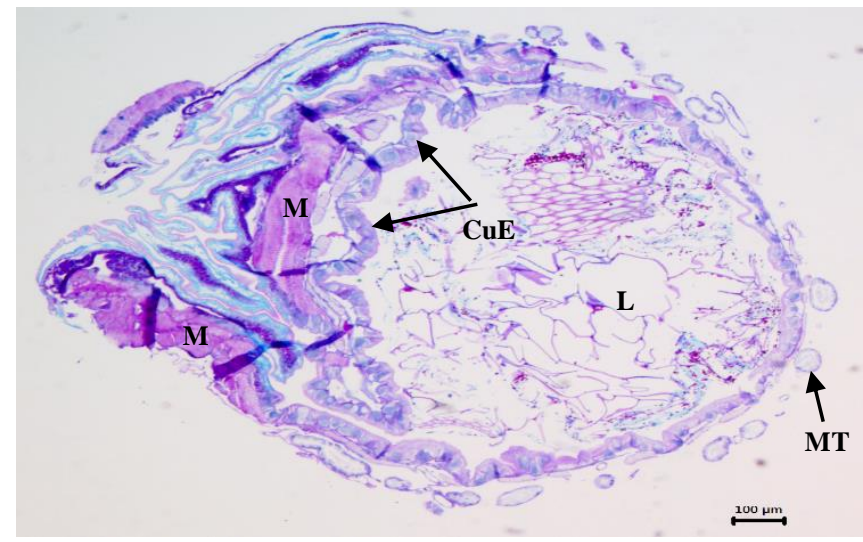

Fig 6 The posterior rectum cell structure of the larvae. Lumen (L); Cuboidal epithelium cell (CuE); Malpighian tubule (MT); Muscle layer (M).

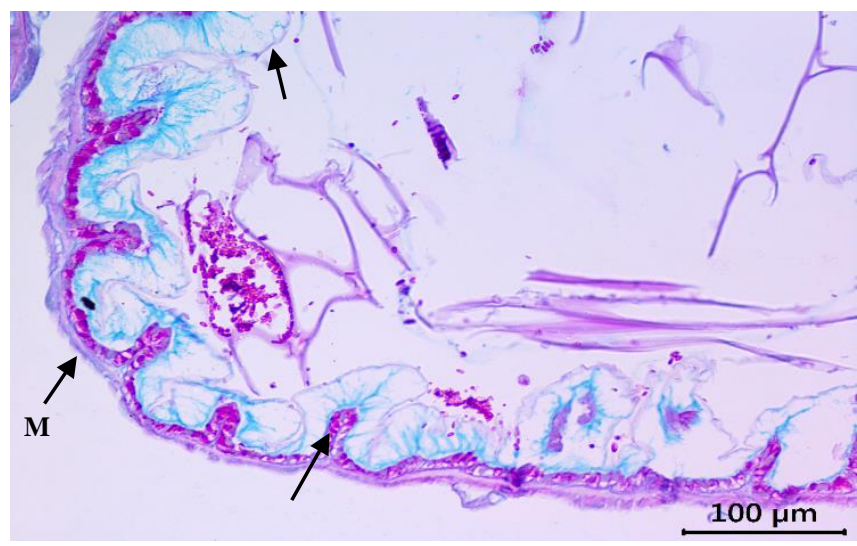

Fig 7 Structure of the rectal pad (Rp) at the arterior rectum. Epithelium layer (Ep); Lumen (L); Muscle layers (M).

The colon is lined up by cuboidal epithelium cell. The similar crytonephridial structure was observed inside and outside of colon cell. However, the lumen of colon were close by abundance structure of collecting tubule like structure of Malpighian tubules that leave only a small opening of colon lumen in the middle. At this part of hindgut may function as the important part for reabsorption of water and useful ion before entering the rectum. It may suggest that the Malphigian tubules invaginate from the colon into the ileum.

While at the rectum there were no invagination of Malphigian tubule as only few can be seen outside the cell. The rectum cell were made up of convalated cuboidal epithelium with a big nucleus structure at the middle of the cell (Fig 6). At the corner of the rectum, a folded formation of epithelium cell were observed. Rectal pads structure were located at the beginning of the rectum that are formed by the enlargement of the cell structure of hindgut (Fig 7). It is common for some of insect groups that have a long hindgut 
structure to increase reabsorption process that are observed in Bombyx mori (Lepidoptera) [13], Rhynchophorus phoenicis (Coleoptera)[19], Scapteriscus borelli (Orthoptera) [18], Stenophylax permistus (Trichoptera) [5] and Blattella germanica (Blattaria) [12]. The epithelium layer of the rectum are seen to be covered with a chitin layer that protect the cell from damage by the friction of the faeces. The rectum have thicker muscle layer surrounding the cell especially at the site where the cell were folded that help in the movement of faeces to be pushed out from the body through anus by peristalsis movement.

\section{CONCLUSSION}

This study have provide a fundamental understanding on the morphology and histology of the digestive system of RPW larva. This knowledge may be the first step to further study to finding the possibility of new treatment to handle the infestation of RPW at the most destructive stage of its life cycle at the palm tree species.

\section{REFERENCES}

[1] Atkins, M. D. 1978. Insect in Perspective. Macmillan Publishing Co. Inc.

[2] Auten.M. 1933. The Structure of the Digestive System in Bolitotherus Cornutus. The Ohio Journal of Science, 33(4), 280-287.

[3] Adedire. C.O. 2002. Functional Morphology of the Alimentary Canal of the Kolanut Weevil, Sophrorhinus insperatus Faust (Coleoptera: Curculionidae). Nig. J. Exp. Appl. Biol, 3, 137-147.

[4] Berridge, M. (2012). Transporting epithelia. Elsevier

[5] Cianficconi, F., Sorcetti, C. C., Moretti, G. \& Dallai, R. 1985. Ultrastructural Organization of the Rectal Pads in Adult Stenophylax Permistus Mcl.(Trichoptera). Italian Journal of Zoology 52(3-4): 375391.

[6] Chapman.R. 1998. The insects: structure and function.

[7] Dembilio.O. \& Jacas. J. A. 2011. Basic bio-ecological parameters of the invasive red palm weevil, Rhynchophorus ferrugineus (Coleoptera: Curculionidae), in Phoenix canariensis under Mediterranean climate. Bulletin of entomological research, 101(2), 153-163. http://dx.doi.org/10.1017/S0007485310000283

[8] Dembilioa.Ó., Llácer.E., Altube.M. del M. M. de \& Jacas.J. A. 2010 Field efficacy of Imidacloprid and Steinernema carpocapsae in a chitosan formulation against the Red Palm Weevil Rhynchophorus ferrugineus (Coleoptera:Curculionidae). Pest Management Science,

[9] Dyar.H. 1890. The number of molts of lepidopterous larvae. Psyche: A Journal of Entomology, http://dx.doi.org/10.1155/1890/23871

[10] Fialho. M. D. C. Q., Zanuncio.J. C., Neves. C. A, Ramalho.S., Serrão.J. E. \& Zanuncio.C. 2009. Ultrastructure of the Digestive Cells in the Midgut of the Predator Brontocoris tabidus (Heteroptera: Pentatomidae) After Different Feeding Periods on Prey and Plants Ultrastructure of the Digestive Cells in the Midgut of the Predator Brontocoris tabidu. Annals of the Entomological Society of America, 102(1), 119-127. http://dx.doi.org/10.1603/008.102.0113

[11] Hood, C. W. 1937. The Anatomy of the Digestive System of Oncopeltus Fasciatus Dall. (Heteroptera: Lygaeidae).

[12] Ishii, S. \& Kuwahara, Y. 1967. An Aggregation Pheromone of the German Cockroach Blattella Germanica L.(Orthoptera: Blattellidae). Applied Entomology and Zoology, 2, 203-217.

[13] Izzetoglu, G. T. \& Ober, A. 2011. Histological Investigation of the Rectal Sac in Bombyx Mori L. Turk J Zool, 35, 213-221.

[14] Jaya, S., Suresh.T., Sobitha-Rani.R. S. \& Sreekumar.S. 2000. Evidence of seven larval instars in the red palm weevil, Rhynchophorus ferrugineus (Oliv.) reared on sugarcane. Journal of Entomological Research, 24, 27-31.

[15] Lopez-Guerrero.Y. 2002. Anatomy and Histology of the Digestive System of Cephalodesmius armiger Westwood. The Coleopterists Bulletin, 56(1), 97-106.

http://dx.doi.org/10.1649/0010065X(2002)056[0097:AAHOTD]2.0.CO;2

[16] Maddrell, S. \& O'Donnell, M. 1992. Insect Malpighian Tubules: VAtpase Action in Ion and Fluid Transport. Journal of experimental biology, 172(1), 417-429.
[17] Mahmoud.M. A., S.A. Hammad \& Mahfouz.M. A. E. 2015. Biological Studies on Red Palm Weevil Rhynchophorus ferrugineus (Olivier) Coleoptera: Curculionidae). Middle East Journal of Applied Sciences, $5(1), 247-251$

[18] Nation, J. L. 2008. Insect Physiology and Biochemistry. USA: Taylor \& Francis Group.

[19] Omotoso.O. T. \& Adedire.C. O. 2010. Gross Anatomy and Histology of the Alimentary System of the Larva of Palm Weevil Rhynchophorus Phoenicis Fabricius (Coleoptera: Curculionidae) Journal of Life Sciences 4(1), 1-5.

[20] Sarwade.A. B. \& Bhawane.G. P. 2013. Anatomical and Histological Structure of Digestive Tract of Adult Platynotus belli. F (Coleoptera : Tenebrionidae), Biological Forum- An International Journal, 5(2), 4755 .

[21] Salama.H. S. \& Abdel-Razek. A. S. 2002. Development of the red palm weevil, Rhynchophorus ferrugineus (Olivier), (Coleoptera, Curculionidae) on natural and synthetic diets. Anzeiger fur Schadlingskunde, 75(5), 137-139. http://dx.doi.org/10.1046/j.1472-8206.2002.02039.x

[22] Stamp. N. 1990. Growth versus molting time of caterpillars as a function of temperature, nutrient concentration and the phenolic rutin Oecologia, 82, 107-113. http://dx.doi.org/10.1007/BF00318541

[23] Silva, C.P, Silva J.R.,Vasconcelos, F.F., Petrestski, M.D., Damatta, R.A., Ribeiro, A.F., \& Terra, W.R. 2004. Occurrence of Midgut Perimicrovillar Membrane in Paraneopteran Insect Orders with Comments on Their Function and Evolutionary Significance. Arthropod Structure and Development. http://dx.doi.org/10.1016/j.asd.2003.12.002

[24] Wrigglesworth. F. \& Wrigglesworth. V. 2015. The Physiology of Insect Metamorphosis. Cambridge University Press.

[25] Wigglesworth. V. 1982. The Principles of Insect Physiology. Dordrecht: Springer Netherlands. http://dx.doi.org/10.1007/978-94-009-5973-6 